\title{
Functional outcomes and rehabilitation strategies in patients treated with chemoradiotherapy for advanced head and neck cancer: a systematic review
}

\author{
Lisette van der Molen • Maya A. van Rossum • \\ Lori M. Burkhead · Ludi E. Smeele • \\ Frans J. M. Hilgers
}

Received: 8 January 2008 / Accepted: 11 August 2008 / Published online: 30 September 2008

(c) The Author(s) 2008. This article is published with open access at Springerlink.com

\begin{abstract}
Organ preservation with radiotherapy and concomitant chemotherapy has become an accepted treatment modality in advanced head and neck cancer. Unfortunately, organ preservation is not synonymous with function preservation. The aim of this review was to systematically assess the effects of the disease and chemoradiotherapy (CRT) on functions such as swallowing, mouth opening, nutrition, pain and quality of life in patients with head and neck cancer. Another aim was to search for (evidence-based) techniques or strategies known to alleviate or rehabilitate
\end{abstract}

L. van der Molen · L. E. Smeele · F. J. M. Hilgers ( $₫)$

Head and Neck Oncology and Surgery,

The Netherlands Cancer Institute, Plesmanlaan 121, 1066 CX Amsterdam, The Netherlands

e-mail: f.hilgers@nki.nl

L. van der Molen

e-mail: m.vd.molen@nki.nl

L. E. Smeele

e-mail:1.smeele@nki.nl

M. A. van Rossum

Otorhinolaryngology, University Medical Centre Leiden, Leiden, The Netherlands

e-mail: m-a.van_rossum@lumc.nl

L. M. Burkhead

Otolaryngology, Medical College of Georgia,

Augusta, USA

e-mail: LBURKHEAD@mail.mcg.edu

F. J. M. Hilgers

Institute of Phonetic Sciences/ACLC,

University of Amsterdam, Amsterdam, The Netherlands

F. J. M. Hilgers

Academic Medical Centre,

Department of Otorhinolaryngology,

University of Amsterdam, Amsterdam, The Netherlands the loss of function(s) associated with CRT. Two databases were searched (time period, January 1997 to August 2007) for the terms head and neck cancer, chemotherapy or cisplatin and radiotherapy, and the functional outcomes swallowing, trismus, nutrition, pain and quality of life or a variation of those words. In total, 15 relevant articles were identified that met the inclusion criteria. The majority of the studies that met the criteria focused on the outcomes swallowing, quality of life, and nutrition. Two studies reported on the outcome pain, but no paper reported on the outcome trismus. Only two papers mentioned rehabilitation options, but specific information was lacking. Further long-term prospective research is essential, not only to determine the function impairment caused by the tumor and CRT, but also to assess the effects of known and newly developed rehabilitation measures. Therefore, in September 2006, the Netherlands Cancer Institute started a randomised clinical trial (RCT): Prevention of trismus, swallowing and speech problems in patients treated with chemoradiotherapy for advanced head and neck cancer. This systematic review was carried out to collect the baseline information for the future outcomes of this RCT.

Keywords Head and neck cancer - Chemotherapy Cisplatin $\cdot$ Radiotherapy $\cdot$ Systematic review .

Functional outcomes $\cdot$ Rehabilitation

\section{Introduction}

Cancer is a major medical health problem worldwide with annually more than 10 million new cases. For head and neck, in 2002 there were 274,000 cases of oral cavity and 159,000 of laryngeal cancer [1] and these numbers are steadily increasing [1]. With the advent of better surgical 
and reconstruction techniques and more effective chemoradiotherapy protocols, oncological outcomes have improved, and thus increasing numbers of patients are confronted with long-term negative side effects of these indispensable therapeutic interventions. Therefore, the development and implementation of evidence-based strategies for the prevention, treatment, and rehabilitation of these side effects are essential [2].

The major head and neck cancer sites are oral cavity, oropharynx, larynx, hypopharynx, and nasopharynx [3]. Depending on the site and stage of the cancer, the treatment may consist of surgery, radiotherapy, chemotherapy or a combination with an increasingly important role for photo dynamic therapy (PDT) $[1,4,5]$. For advanced cases, there has been a shift from surgical treatment towards chemoradiotherapy protocols (especially concomitant chemotherapy and radiotherapy, CRT). These organ preservation protocols, developed to maintain organ anatomy [6-12], unfortunately do not necessarily preserve the organ's function $[5,6,10,13,14]$. The toxicities of these combined therapies are often severe and include xerostomia, pain, mucositis, fatigue, as well as late effects such as limited mouth opening (trismus) $[15,16]$. Fibrosis and muscle atrophy may also occur which can affect swallowing as it causes, for example, fixation of the hyolaryngeal complex and reduced glottic closure, potentially resulting in aspiration $[15,17]$. Rehabilitation that prevents and/or alleviates the loss of function and increases the patients' quality of life therefore seems necessary. Several specific swallowing exercises have the potential to improve prognosis for oral intake (e.g., jaw exercises [18], swallowing exercises [19] and maneuvres) [17, 20, 21]. It is, however, unknown whether these standard exercises have a preventative effect in patients receiving CRT and whether the effects, if any, are maintained long-term.

The first aim of this review was to examine the literature to determine the effect of the tumor and CRT on functions such as swallowing, mouth opening, nutrition, as well as quality of life and pain. A second aim was to search for (evidence-based) therapy techniques and strategies that may alleviate or even rehabilitate loss of function.

\section{Methods}

Electronic databases, Pubmed and Cochrane were searched for the MeSH terms 'chemotherapy or cisplatin and radiotherapy', 'head and neck cancer', 'dysphagia or swallowing disorders or swallowing dysfunction or deglutition', 'trismus or limited mouth opening or mouth opening', 'quality of life or QOL or questionnaire', 'oral intake or nutrition or diet or weight changes or eating disability' and 'pain or VAS scale'.
Inclusion criteria

Included in this review were clinical studies published from 1 January 1997 until 1 August 2007, written in Dutch, German and English. Other limits were human and adults $(18+$ years $)$. Studies were included if they were research based, published in a peer-reviewed journal, and reported the use of concomitant chemoradiotherapy without any other treatment modality for head and neck cancer. Included studies had to report about functional problems or rehabilitation options related to swallowing, trismus, quality of life, nutrition or pain. In addition, retrospective or prospective studies that reported pre and postmeasurements were also included.

\section{Exclusion criteria}

The following material was excluded: texts or practice guidelines; studies that only reported outcomes related to surgery, radiotherapy alone, radiotherapy followed by chemotherapy or other kinds of drugs used during the treatment; studies describing cancers other than primary cancer in the oral cavity, nasopharynx, oropharynx, larynx or hypopharynx; studies only reporting outcomes related to survival, toxic effects or general function (e.g. depression). The intent of this review was to report on functional outcomes and/or rehabilitation options after CRT, thus, details related to surgical interventions, except the possible influence of neck dissection, were not reviewed.

In total, 575 papers were identified in the databases. Of these papers, 137 occurred more than once. The first author read the remaining 438 abstracts. Using the search strategy, 63 different papers were initially identified as suitable (Fig. 1) [9, 10, 13, 14, 22-80].

Two observers (LvdM and MR) assessed the selected papers independently, according to specific criteria designed for this study (Table 1): location of tumor, population (i.e., $N>10$ ), intervention, and outcome. Reference lists from the selected review papers were analyzed for other relevant citations [29, 75, 77]. These were then obtained and subjected to the same process as the articles retrieved from the database search. Of all references searched manually, only one additional paper was selected [81].

Finally, 15 papers answered all four specific criteria with (yes) $[13,22,23,27,34,40,42,45,51,52,59,60,65,69$, 81] (Fig. 1). ${ }^{1}$

\footnotetext{
${ }^{1}$ A complete list of the papers retrieved from the databases is available from the corresponding author. The fifteen papers 'surviving' the predefined 'quality' criteria are listed in bold and the papers collected after the reviewed period are listed bold and italic.
} 
Fig. 1 Search strategy

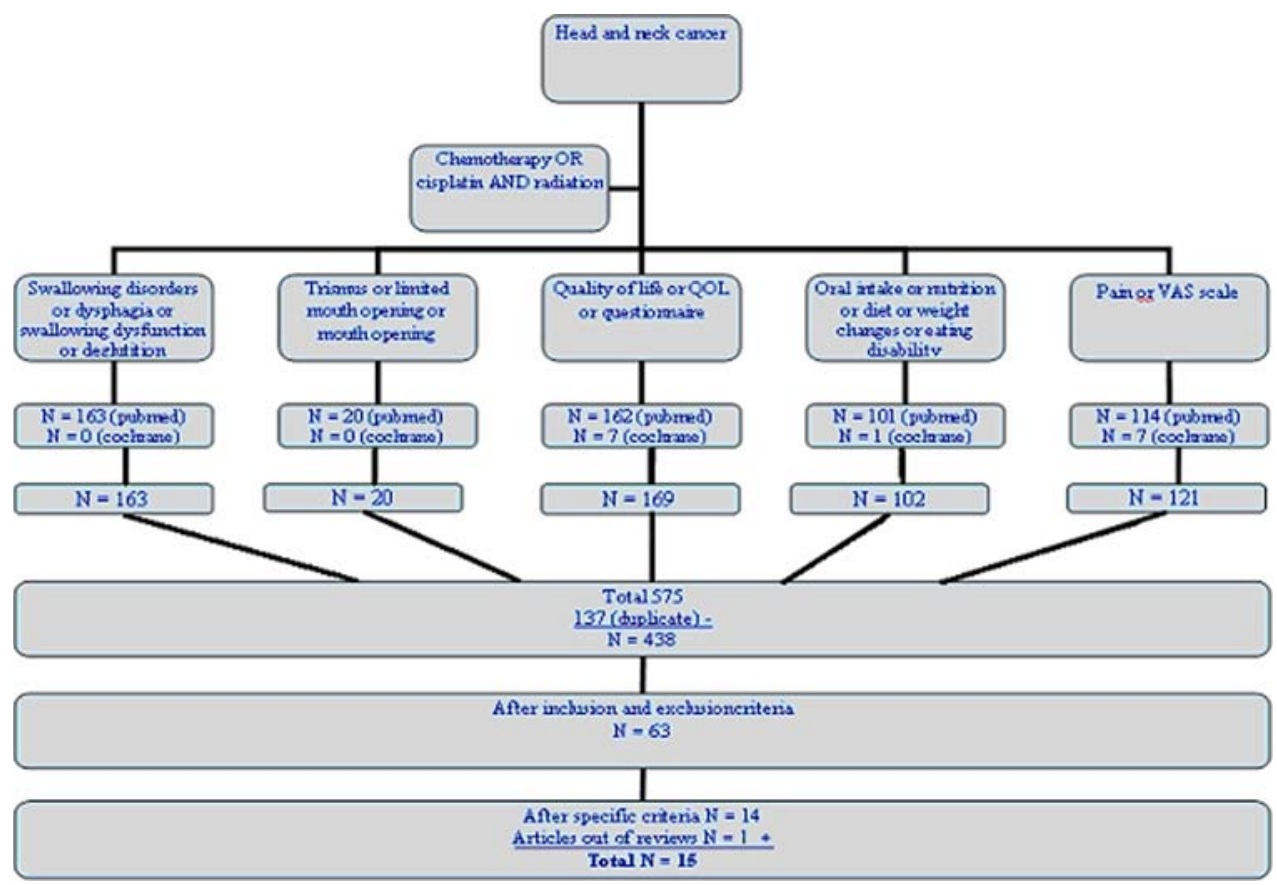

Table 1 Quality criteria

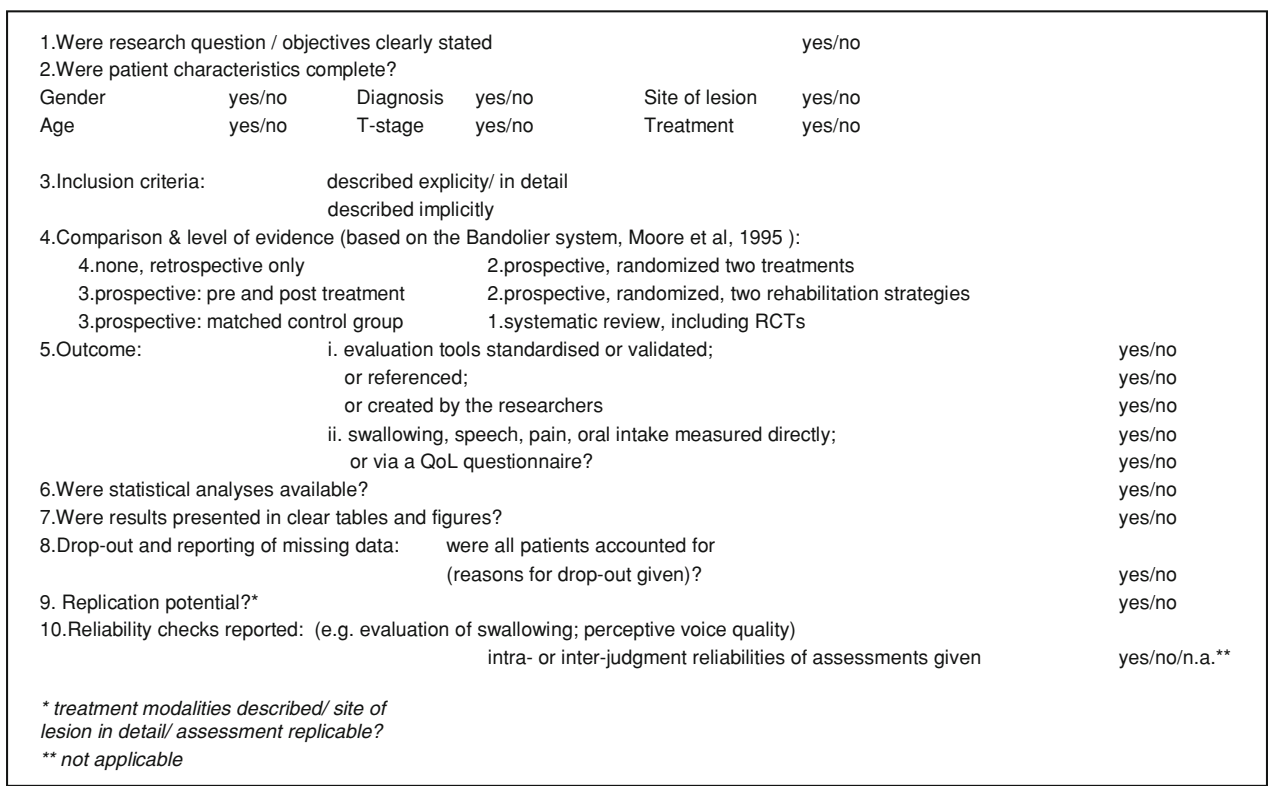

\section{Results}

The results of the selected fifteen papers will be discussed in the following order: general findings, relationships between chemoradiotherapy (CRT) and swallowing, quality of life, trismus, nutrition, and pain. Since all these papers discuss more than one of the issues listed here, they will occur when relevant. An overview of these papers and the aspects they have reported are presented in Table 2.
General findings

Reported sites across all 15 articles included oral cavity (10/15), nasopharynx (6/15), oropharynx (12/15), hypopharynx (11/15) and larynx (13/15). Two studies also included patients with unknown primaries [13, 52], one also included paranasal sinuses [27], another included thyroid, paranasal sinus, and external ear cancer [81] and one included a group with diverse disease sites (e.g., parotid, ethmoid cavity, and unknown primary) $[13,27,51,52,81]$. 
Table 2 Overview across all 15 studies

\begin{tabular}{|c|c|}
\hline Review criteria & Results \\
\hline \multicolumn{2}{|l|}{ Site of lesion } \\
\hline Oral cavity & $10 / 15$ \\
\hline Nasopharynx & $6 / 15$ \\
\hline Oropharynx & $12 / 15$ \\
\hline Hypopharynx & $11 / 15$ \\
\hline Larynx & $13 / 15$ \\
\hline Total number of patients (range) & $709(11-166)$ \\
\hline \multicolumn{2}{|l|}{ Intervention } \\
\hline Treatment & $15 / 15$ \\
\hline Rehabilitation & $1 / 15$ \\
\hline \multicolumn{2}{|l|}{ Outcome } \\
\hline Swallowing/dysphagia & $8 / 15$ \\
\hline Quality of life & $8 / 15$ \\
\hline Trismus/range of jaw & $0 / 15$ \\
\hline Nutrition/intake/diet/body weight & $7 / 15$ \\
\hline Pain & $2 / 15$ \\
\hline \multicolumn{2}{|l|}{ Patient characteristics mentioned } \\
\hline Gender & $13 / 15$ \\
\hline Age & $14 / 15$ \\
\hline Diagnosis & $15 / 15$ \\
\hline T-stage & $8 / 15$ \\
\hline Site of lesion & $3 / 15$ \\
\hline Treatment & $15 / 15$ \\
\hline \multicolumn{2}{|l|}{ Inclusion criteria } \\
\hline Explicit & $12 / 15$ \\
\hline Implicit & $3 / 15$ \\
\hline \multicolumn{2}{|l|}{ Level of evidence } \\
\hline 4. None, retrospective only & $0 / 15$ \\
\hline 3. Prospective: pre and postmeasurement & $11 / 15$ \\
\hline 3. Prospective: matched control group & $0 / 15$ \\
\hline 2. Prospective, randomised two treatments & $4 / 15$ \\
\hline 2. Prospective, randomised, two rehabs & $0 / 15$ \\
\hline 1. Systematic review, including RCTs & $0 / 15$ \\
\hline Evaluation tools standardized or validated & 12 \\
\hline Referenced & 1 \\
\hline Created & 2 \\
\hline \multicolumn{2}{|l|}{ Swallowing, trismus, pain etc. } \\
\hline Measured directly & 8 \\
\hline Or via QOL questionnaire & 5 \\
\hline Statistical analyses available & $13 / 15$ \\
\hline Results presented in clear tables and figures & $15 / 15$ \\
\hline \multicolumn{2}{|l|}{ Drop-out and missing data reported } \\
\hline Yes & $8 / 15$ \\
\hline No & $7 / 15$ \\
\hline Replication potential & $5 / 15$ \\
\hline Reliability checks reported & $3 / 15$ \\
\hline
\end{tabular}

Values represent number of studies unless otherwise specified
The number of patients receiving CRT that completed both pre and posttreatment measurements varied per study. Follow-up also varied, from immediately after treatment to 5 years posttreatment. Four articles also evaluated outcomes during CRT [22, 27, 34, 51]. All articles reported on treatment except two, that reported on swallowing rehabilitation [40, 64]. However, detailed information about the type of rehabilitation was not reported. All the articles stated clear research questions and/or objectives. Patient's characteristics were not available in three studies [27, 69, 81]. In one of these studies, the authors referred to a previous publication for those data [81] [82]. The T-stage was reported in 8 of the 15 articles [13, 23, 27, 40, 42, 52, 59, $60,69]$. Several studies described only the overall stages (III-IV). Exact sites of lesions were only reported in three studies and included tonsil/lateral oropharynx, base of tongue, floor of mouth, tongue, retromolar trigone/alveolar process, transglottic or supraglottic larynx/vallecula, pharyngeal wall, pyriform sinus/hypopharynx, glottic and buccal mucosa tumors [23, 45, 59]. In most of the studies, the inclusion criteria were described in detail.

The level of evidence of each study was graded using a four-point-scale, based on the Bandolier system [83]. Only two levels occurred, 3. prospective, pre and postmeasurement and 2. prospective, randomized, two treatments. Statistical analyses and results were available and presented in clear tables and figures in most articles. Three of the five studies mentioned inter- and intra-observer reliability of videofluoroscopic modified barium swallow examination (VMBS) [13, 40, 42, 52, 60]. For the other ten studies $(67 \%)$ this aspect was not applicable. Nine of 15 studies $(60 \%)$ reported reasons and extent of missing data, such as patient drop out and death $[4,22,23,27,34,42,45,51,60$, 65]. Replication of two-thirds of these 15 studies would not be possible as a result of missing information about patients, and assessment methods.

Because of the main intent of this review, details related to speech outcomes were not reviewed. Besides the outcomes mentioned above, aspiration, swallowing therapy, body weight, and tube feeding were assessed as well.

CRT and swallowing

Eight of the reviewed articles reported on swallowing function $[13,40,42,45,52,60,65,81]$. Two studies used a patient self-report questionnaire or a standardized qualityof-life questionnaire $[40,45]$. Both the studies concluded that the patients' abnormal swallowing, although improved, was still present after 18 and 24 months. Goguen et al. [40] used also a videofluoroscopy examination, but only examined patients who had increased or protracted dysphagia after treatment. 
Six papers assessed swallowing via VMBS $[13,42,52$, $60,65,81]$. All six studies reported several swallowing abnormalities before treatment. The majority of studies found the same disorders after CRT (range of follow-up: 112 months for all studies), but in higher frequencies and in greater severity. Logemann et al. [52] reported details of the frequencies that occurred. Fifty-three subjects contributed 351 'swallows' to the analysis before CRT. Swallow disorders of varying severity occurred in the following frequencies (percent of swallows in decreasing order): reduced tongue base retraction $(50 \%)$, reduced tongue strength (39\%), slowed/delayed laryngeal vestibule closure (19\%), reduced tongue control/shaping (17\%), delayed pharyngeal swallow (up to 30-s delay; 15\%), reduced laryngeal elevation $(13 \%)$, reduced manipulation and propulsion of the bolus (reduced AP tongue movement; $12 \%$ ), reduced lateral/anterior tongue stabilization (7\%), bilateral pharyngeal weakness $(5 \%)$, reduced vertical tongue movement $(5 \%)$, reduced cricopharyngeal opening (3\%), visible cricopharyngeal bar (2\%), and unilateral pharyngeal weakness (2\%). At 3 months posttreatment, 53 patients contributed 310 swallows to the analysis, and the most frequently occurring disorders were reduced tongue base retraction (89\%), reduced tongue strength (51\%), and slowed/delayed laryngeal vestibule closure (31\%). The following disorders occurred in less than $5 \%$ of the swallows: reduced lateral/ anterior tongue stabilization (5\%), incomplete laryngeal vestibule closure $(5 \%)$, reduced velopharyngeal closure $(4 \%)$, reduced vertical tongue movement (3\%), and reduced glottic closure $(1 \%)$. The other five studies did not report any additional swallowing abnormalities. One study found no obvious swallowing differences between early and late posttreatment (1-3 and 6-12 months after CRT) [81]. Overall, the swallowing problems after CRT were moderate to very severe.

Two studies reported a relationship between swallowing difficulties and tumor site [52, 81]. Logemann et al. [52] found that tumors in the nasopharynx had the highest frequency of reduced oral tongue control. Tumors of the oropharynx exhibited a high frequency of reduced tongue base retraction, and reduced tongue strength. Tumors of the larynx had the highest frequency of reduced tongue base retraction, reduced anterior posterior tongue movement, delayed pharyngeal swallow, reduced laryngeal elevation, and reduced cricopharyngeal opening. Tumors of unknown origin had a high frequency of reduced laryngeal elevation, reduced cricopharyngeal opening, and visible cricopharyngeal bar in spite of the fact that those patients received the lowest average radiotherapy dose. However, no explanation was attempted for this somewhat unexpected finding. Eisbruch et al. [81] noted that swallowing abnormalities were related to the stage of the primary tumor and its location, but the advanced stage of all tumors (stage III/IV) and the predominance of oropharyngeal primary tumors (14 of the 26 patients) precluded an analysis of these factors in their study.

Nguyen et al. [65] also examined the swallows using VMBS, relying on the swallowing performance scale (SPS) to evaluate the severity of the swallow abnormalities pre and posttreatment $[65,84]$. These authors found that 27 patients $(43 \%)$ had severe swallowing problems (grades $3-$ 7) before treatment, and after treatment (range 110 months) this number increased to 48 patients $(84 \%)$.

Number of neck dissections was reported in two studies [40, 42]. Graner et al. [42] reported that seven patients with neck dissections had significantly worse laryngeal elevation compared to the four patients who did not undergo this surgery.

\section{Aspiration}

Seven studies analyzed the aspiration rate $[13,22,40,42$, $52,60,65,81]$. The aspiration rate increased over time in all studies. Eisbruch et al. [81] found that 3 of the 22 patients (14\%) aspirated pretreatment, whereas 17 of 25 (68\%) demonstrated aspiration in at least one of the posttreatment measurements. Kotz et al. [13] reported no aspiration in 12 patients before treatment compared to the 4 patients $(33 \%)$ after treatment. This difference was, however, not significant. Graner et al. [42] noted aspiration in 3 of 11 patients $(27 \%)$ before treatment. Two of these patients did not exhibit a cough reflex in response to material entering the airway. After CRT (on average, 19 weeks), seven patients $(64 \%)$ aspirated and six of them had no cough reflex in response to material entering the airway. In the study by Nguyen et al. [64] $(N=63)$, three patients presented trace aspiration and seven severe aspiration at diagnosis (17\% in total). Following treatment, 31 patients (49\%) aspirated. The aspiration attributed to CRT was 21 of the 63 patients (33\%), which is a significant increase in aspiration rate. Logemann et al. [52] also found an increase in aspiration rate. Four patients $(8 \%)$ aspirated before treatment and 12 patients (23\%) after 3 months. These authors also found that patients with lesions in the hypopharynx or larynx most frequently aspirated before treatment when compared with the other sites of disease. None of the other studies mentioned differences by site of disease.

In two studies, pretreatment examination is missing [40, 60]. Newman et al. [60] described the aspiration rate per bolus type, 1 month after treatment. Goguen et al. [40] performed MBS when the perceived swallowing difficulties were beyond that expected after treatment and found that 18 of 23 patients $(78 \%)$ aspirated. Silent aspiration was seen in $8(35 \%)$ of these 23 cases.

In three studies, aspiration pneumonia occurred [22, 65, 81]. Abdel-Wahab et al. [22] reported three cases (13\%) of 
aspiration pneumonia as a late complication of CRT. Eisbruch et al. [81] found that 5 of the 17 cases (29\%) with aspiration on MBS developed aspiration pneumonia and of these 5, 2 died from their pneumonia. Nguyen et al. [65] reported six patients (10\%) who died from aspiration pneumonia [one before, three during, and two after CRT (1-10 months)]. They also concluded that aspiration remained a significant morbidity of CRT for head and neck cancer patients.

\section{Swallowing therapy}

Two studies started swallowing therapy after VMBS in patients with an abnormal swallow [40,65]. In the study by Goguen et al. [40], swallow therapy was undertaken by all patients who showed laryngeal penetration without aspiration. Exact details about the therapy were unavailable. Nguyen et al. [65] reported that patients with severe swallowing problems underwent swallow therapy immediately following VMBS, prior to treatment. The swallowing therapy was individualized for each patient. The therapy consisted mostly of maneuvres to improve the efficiency and/or airway protection during the swallow. Patients identified with an anatomic abnormality during the VMBS also applied range of motion exercises. Based on posttreatment VMBS, these authors concluded that the swallowing therapy was frequently effective in stopping aspiration.

\section{CRT and quality of life}

Eight of the reviewed papers reported on quality of life questionnaires. [22, 23, 27, 34, 40, 42, 51, 69], using at least one of the following standardized quality-of-life questionnaires: the University of Washington Quality of life questionnaire (UWQol) [85], the Functional Assessment of Cancer Therapy-General (FACT-G) [86], the Functional Assessment of Cancer Therapy- Head and Neck questionnaire (FACT-HN) [86, 87], the Quality of Life Questionnaire C-30 (QLQ-C30) [88-90], the Quality of Life Questionnaire-Head and Neck 35 (QLQ-HN35) [30, 91, 92], the European Organisation for Research and Treatment of Cancer (EORTC/RTOG) [85, 93, 94], and the Performance Status Scale for Head and Neck Cancer Patients (PSS-HN) [95, 96]. Most of the studies reported significant improvement for most questionnaire scales over time.

Cohen et al. [34] found adverse effect symptoms (e.g. dry mouth, pain, sticky saliva, hoarseness) during treatment as well as a significant decline on performance items (e.g. normalcy of diet, eating in public), FACT physical, functional, head and neck subscales, and overall FACT-General global QOL. The majority of scores returned to baseline levels by 12 months.

List et al. [51] and Abdel-Wahab et al. [22] also measured an improvement at 12 months posttreatment, but List et al. [51] reported that symptoms such as dry mouth, tasting difficulties and soft food diet still occurred at 12 months. Patients also showed persistent difficulties in the ability to eat all solid foods. Abdel-Wahab et al. [22] reported a significant decrease in mean scores (FACT-G) during and immediately after CRT followed by a significant increase 6 months postCRT. The Total FACT-HN scores reflected a significant decrease in QOL for the first 3 months, but this gradually increased, even 1 year postCRT.

Arraras Urdaniz et al. [27] described significant differences between the first day of treatment and 1 month after completing the treatment using the QLQ-C30 and QLQ$H \& N 35$. Differences were found in, for example fatigue (C30), and in, for example dry mouth, decreased mouth opening, social eating, sticky saliva, swallowing difficulties, and dental problems (H\&N35). Comparison between the last part of treatment and one-month posttreatment revealed significant differences, amongst others, in pain, swallowing difficulties, dry mouth, tube feeding and weight loss.

In contrast to the other studies, Oates et al. [69] reported poorer quality-of-life scores for global health during the 24 months of follow-up; patients had progressive problems with teeth, trismus, xerostomia, swallowing and social eating. However, this study only included 14 patients with nasopharyngeal cancer.

There were no differences mentioned with respect to sex, age, tumor site, or stage in any of the other studies.

\section{CRT and trismus}

Table 2 shows that none of the studies mentioned anything about the outcome trismus or limited mouth opening. Of the 63 collected papers, only 1 evaluated the occurrence of trismus [71]. However, this article had to be excluded from the final analysis because there were only seven patients who received CRT, and the results of this group were not assessed separately.

\section{CRT and nutrition}

Seven papers analyzed the effect of CRT on nutrition [40, $42,45,51,52,59,69]$, of which four used validated questionnaire (QOQ-C30, FACT-H\&N or PSS-HN) [40, 42, 51, 69].

List et al. [51] reported that $30(51 \%)$ of the patients were eating a normal, unrestricted diet pretreatment. Twelve patients $(20 \%)$ were eating soft foods only, six $(10 \%)$ were taking liquids only, and seven $(12 \%)$ were limited to non-oral intake. During treatment, there was a marked decrease in the Normalcy of Diet subscale of the PSS-HN. Comparing pre and posttreatment soft food diet 
occurred more frequently at 12 months posttreatment (82\% post vs. $42 \%$ pretreatment).

Graner et al. [42] reported that $9(82 \%)$ of the 11 patients reported no restrictions. After treatment, all patients but one (90\%) described increased diet restrictions. Moreover, seven $(64 \%)$ were taking less than $50 \%$ of nutrition orally and relied on tube feeding as the primary means of nutritional intake. In addition, restrictions in eating in public and in normalcy of diet increased significantly.

Goguen et al. [40] also described a decrease of oral intake at 3 months. Only ten patients (17\%) took a soft or regular diet. After 12 months, this number increased to 47 of all patients (80\%).

Oates et al. [69] found that oral feeding during treatment with chemotherapy was the major problem, because patients experienced nausea associated with chemotherapy and were often unable to meet their nutritional requirements.

The other two studies measured nutrition using a scale or a limited number of questions [45, 59]. Newman et al. [59] used a 4-point scale created by the authors to measure the eating ability of the patients. These authors found that at the start of treatment, 18 patients (38\%) reported normal eating and $4(8 \%)$ required a feeding tube. Eighteen months after treatment, 41 patients (87\%) were eating normally, with 34 (72\%) reporting normal swallowing and $6(13 \%)$ still required a feeding tube.

Hillman etal. [45] only measured diet textures as reported by the patients. At randomisation, $27-30 \%$ of the 44 patients who received CRT reported modifications in diet texture. At 24 months posttreatment, only 21 patients $(13 \%)$ reported modifications in diet texture.

Overall, most studies reported some pretreatment changes in diet, a decrease in oral intake during treatment, and improved oral intake after 12-18 months posttreatment.

\section{Body weight}

The three papers evaluating body weight reported weight loss during and after treatment [40, 59, 69]. Newman et al. [59] reported a significant $10 \%$ weight loss of pretherapy body weight during treatment and a subsequent gain in mean weight after treatment. After 18 months, the mean weight loss, however, was still $8 \%$.

Oates et al. [69] also reported a weight loss with a median of $8.2 \mathrm{~kg}$ (range $2.3-13.9 \mathrm{~kg}$ ), representing a proportional weight loss of $4-17 \%$ during treatment. Weight loss occurred despite support with enteral tube feeding. The median weight loss during the full 2 years was $7 \mathrm{~kg}$ (range $2.3-17.3 \mathrm{~kg}$ ) or $7.9 \%$ (range 3-22\%). Goguen et al. [40] found a median weight loss of $9.6 \mathrm{~kg}(12.7 \%)$. Unfortunately, no long-term results or statistical analyses were available for this latter study.
Tube feeding

Seven papers reported on tube feeding [22, 23, 40, 42, 52, $59,69]$. In six studies, placement occurred prior or during the first week of treatment [22, 23, 42, 52, 59, 69]. Only Goguen et al. [40] performed placement after induction chemotherapy. The number of patients with feeding tubes varied from study to study. In the study by Newman et al. [59], 4 patients (9\%) had a feeding tube at the start of the CRT, compared to 12 patients (26\%) at completion. Logemann et al. [52] reported eight patients (15\%) with a gastrostomy tube before treatment and three patients $(6 \%)$ taking $50 \%$ or less of their nutrition orally. In the study of Oates et al. [69], 13 patients (93\%) required a gastrostomy tube for nutritional support during treatment. Graner et al. [42] reported that all patients were taking oral nutrition before treatment, but eight patients $(73 \%)$ had feeding tubes placed either before or during their treatments because of increased dysphagia. Also Ackerstaff et al. [23] reported that many patients used tube feeding at some time during and/or after their treatment, but gave no numbers. In the study by Abdel-Wahab et al. [22] and Goguen et al. [40] all patients had to accept gastrostomy placement prior to or during the first week of treatment.

All studies measured a decrease of gastrostomy tube dependency posttreatment. Ackerstaff et al. [23] reported that most patients regained more or less normal oral feeding, but five patients (19\%) still needed tube feeding at 1year follow-up: three because they had mastication problems, although drinking liquids was still possible, and two because they could hardly swallow. Goguen et al. [40] described that only $2(3 \%)$ of 59 patients still had their tubes after 2 years, one patient because of palliative chemotherapy and one patient because he preferred keeping his gastrostomy tube. In the study by Abdel-Wahab et al. [22], 17 of the $21(81 \%)$ were able to swallow solids 1year posttreatment, and all patients were independent of tube feeding at 48 months. Newman et al. [59] looked at 6 , 12 and 18 months posttreatment, and they found that the need for a gastrostomy tube dropped to $13 \%$ (6 patients). These authors concluded that subjects, who still had a feeding tube after 6 months, were also dependent on tube feeding after 12 and 18 months. Graner et al. [42] found that seven patients $(64 \%)$ were relying on tube feeding for more than $50 \%$ of their nutrition and hydration 5 months after treatment, and Logemann et al. [52] reported that 21 patients (40\%) used tube feeding and 12 patients (23\%) were taking $50 \%$ or less of their nutrition orally after 3 months. Finally, in the study by Oates et al. [69], all feeding tubes except one $(8 \%)$ were removed 6 months after treatment.

Overall, just one study reported that all patients were no longer dependent on tube feeding after 4 years [22]. The 
other studies still reported a varying level of tube feeding dependency up to 18 months after treatment.

\section{CRT and pain}

Two studies mentioned outcome (pain) in relation to the CRT [23, 34]. In both the studies, pain was measured using a standardized quality-of-life questionnaire (UWQol and FACT-G). Ackerstaff et al. [23] reported that 3 months posttreatment, 12 patients (46\%) needed regular (non-narcotic) medication, and 2 patients (8\%) suffered from severe pain that had to be controlled by narcotics. [23] After 12 months, only five patients (19\%) still required regular medication for the pain. Cohen et al. [34] also reported a significant improvement in pain, 12 months posttreatment compared to pretreatment [34].

\section{Discussion}

\section{General}

This review covered two research questions: (1) what are the negative side effects of concomitant CRT on swallowing, mouth opening, pain and quality of life before and after treatment in head and neck cancer patients and (2) what are the rehabilitation options to ameliorate these side effects? Fifteen papers were identified that could be assessed according to a predefined set of 'quality' criteria. The majority of these articles focussed on the outcomes swallowing, quality of life and nutrition, but also on trismus and pain.

In most papers, swallowing was assessed by means of videofluoroscopy modified barium examination (VBMS). The most common abnormalities at baseline included reduced posterior motion of the base of tongue, delay in the swallow reflex, decreased epiglottic movement, decreased laryngeal elevation, and bolus residue in the vallecula or posterior pharyngeal wall after the completion of the swallow. The same swallowing abnormalities occurred after CRT, but in higher frequencies and in greater severity. Even 1-year posttreatment, swallowing abnormalities still existed. Tumors in the nasopharynx were associated with trismus and reduced oral tongue control. Oropharynx tumors exhibited a high frequency of reduced tongue base retraction and reduced tongue strength and patients with lesions in the larynx most frequently exhibit reduced tongue base retraction, reduced anterior posterior tongue movement, delayed pharyngeal swallow, reduced laryngeal elevation, and reduced cricopharyngeal opening. In addition, CRT seems to increase the aspiration rate, and neck dissections seem to worsen laryngeal elevation.
Most of the reviewed studies were not designed to examine the effects of swallowing therapy, and therefore did not focus on rehabilitation options. Many tongue and swallowing exercises, such as tongue function therapy and swallowing maneuvres, are described in the literature [17, 21, 48, 97-102]. Furthermore, the effectiveness of these swallowing exercises has not yet been assessed systematically in the CRT patient population.

After the designated period of this systematic search had ended, several additional papers were published, three of which (Carroll et al. [97], Logemann et al. [103] and Langerman et al. [104]) warrant a brief review. Carroll et al. and Logemann et al. suggested that (early) rehabilitation might be beneficial. Unfortunately, only limited numbers of patients were involved and neither of these two studies was a randomized clinical trail. Langerman et al. [104] retrospectively reviewed the incidences of aspiration after CRT in 130 patients, and concluded that aspiration rate increases over time. They also found that the patients with cancer of the larynx and hypopharynx were more likely to be frank aspirators (more than 5\% of the swallowed bolus was aspirated).

Quality of life research in the 15 assessed papers was generally well conducted, which is not surprising in view of the many well-designed and validated questionnaires presently available. In general, all papers reported that the overall quality of life scores improved over time and returned to baseline 1 year postCRT.

To evaluate nutritional support, all the reviewed papers used questionnaires or a 4-point-scale. Some studies reported a gradual improvement of oral intake over time and the majority of patients had returned to baseline levels by 12 months. One study reported what might be a good predictor; if the swallow is normal at 6 months posttreatment, it will also be normal at 12 and 18 months [59]. The data also suggest that the act of eating and swallowing itself may 'rehabilitate' the oropharyngeal musculature necessary for swallowing. In other words, keeping the muscles active will keep the muscles useful.

We conclude that this systematic search of the literature provides an answer to the first research question, but that the second question remains unanswered.

\section{Limitations of current studies}

Missing information, e.g. about gender, site of lesion, and assessment methods precludes replication in two-thirds of the studies. There was also little uniformity in follow-up times and evaluation tools. Because missing data (dropouts) could have biased the results, lack of this information is considered a limitation. In addition, only three of the five relevant papers reported intra- or interobserver reliability checks of VMBS. 
Data on the effects on mouth opening after CRT is lacking, and in view of the more pronounced side effects of CRT in comparison to RT alone, more reports were expected.

Finally, papers on rehabilitation options and their effects are very sparse. Most studies focussed on the functional outcomes after CRT, but not on possible rehabilitation options. The tradition of evidence-based rehabilitation after organ sacrificing therapies, such as total laryngectomy, has been well-established and the time has now come to invest in evidence-based rehabilitation after CRT [105].

Future directions

It is clear from the present systematic review that head and neck cancer patients suffer from substantial function losses after CRT. This implies that not only the various functions at stake pre and posttreatment should be measured multidimensionally but also that centers should strive at performing these measures with the same standardized, validated instruments. In addition, prevention and rehabilitation of loss of function should be investigated on a much wider scale. The guidelines of the Dutch Cooperative Group on Head and Neck Cancer already recommended preventative management of trismus and dysphagia [3]. Other authors also emphasize the importance of rehabilitation $[5,13,15$, 40].

Besides the swallowing intervention, rehabilitation of trismus should be given attention. Dijkstra et al. [18] documented that, the effects of therapeutic interventions of trismus are hardly investigated and evidence supporting prevention and treatment programs is generally not provided. Nevertheless, one randomised trial in patients who had undergone radiotherapy for cancer of the head and neck showed that standard stretching exercises with or without the use of tongue depressors, and exercises with the passive jaw moving device TheraBite, did increase mouth opening significantly [106]. As far as we know, it has not been established if either standard stretching exercises or passive movement using the TheraBite can prevent trismus. Burkhead developed an exercise regimen incorporating the TheraBite device, and found an increased neuromuscular activation of the swallowing muscles (Effect of tongue and jaw position on suprahyoids during swallowing. Paper presented at the ASHA Convention, session 1377, November 2004).

It is, however, uncertain at present which rehabilitation procedures have the best preventative and long-term effect in decreasing functional problems such as swallowing, mouth opening, pain and quality of life in patients with head and neck cancer receiving CRT. The Netherlands Cancer Institute started a Randomised Clinical Trail (prevention of trismus, swallowing and speech problems in patients treated with chemoradiotherapy for advanced head and neck cancer in September 2006). This study compares exercising with or without a device, and investigates if either approach has a preventative or and long-term effect (1-year postCRT) on jaw motion and swallowing function.

Conflict of interest statement The authors declare that they have no conflict of interest.

Open Access This article is distributed under the terms of the Creative Commons Attribution Noncommercial License which permits any noncommercial use, distribution, and reproduction in any medium, provided the original author(s) and source are credited.

\section{References}

1. Parkin DM, Bray F, Ferlay J, Pisani P (2005) Global cancer statistics, 2002. CA Cancer J Clin 55:74-108

2. World Health Organisation (2005).WHO Cancer Control Strategy 2005. Global programming note 2005-2007 CFRMAEO (2 A.D.). Retrieved in January 2007

3. Nederlands werkgroep hoofd-halstumoren (Dutch Cooperative Group on Head and Neck Cancer) (2005) Richtlijn Mondholte en orofarynxcarcinoom. Van Zuiden, Alphen a/d Rijn, pp 173-199

4. Copper MP, Tan IB, Oppelaar H, Ruevekamp MC, Stewart FA (2003) Meta-tetra(hydroxyphenyl)chlorin photodynamic therapy in early-stage squamous cell carcinoma of the head and neck. Arch Otolaryngol Head Neck Surg 129:709-711

5. Ward EC, van As-Brooks CJ (2007) Head and neck cancer, treatment, rehabilitation, and outcomes. Plural Publishing, San Diego

6. Mittal BB, Pauloski BR, Haraf DJ, Pelzer HJ, Argiris A, Vokes EE, Rademaker A, Logemann JA (2003) Swallowing dysfunction-preventative and rehabilitation strategies in patients with head-and-neck cancers treated with surgery, radiotherapy, and chemotherapy: a critical review. Int J Radiat Oncol Biol Phys 57:1219-1230

7. Lee WT, Akst LM, Adelstein DJ, Saxton JP, Wood BG, Strome M, Butler RS, Esclamado RM (2006) Risk factors for hypopharyngeal/upper esophageal stricture formation after concurrent chemoradiotherapy. Head Neck 28:808-812

8. Urba S, Wolf G, Eisbruch A, Worden F, Lee J, Bradford C, Teknos T, Chepeha D, Prince M, Hogikyan N, Taylor J (2006) Single-cycle induction chemotherapy selects patients with advanced laryngeal cancer for combined chemoradiotherapy: a new treatment paradigm. J Clin Oncol 24:593-598

9. Allal AS, Nicoucar K, Mach N, Dulguerov P (2003) Quality of life in patients with oropharynx carcinomas: assessment after accelerated radiotherapy with or without chemotherapy versus radical surgery and postoperative radiotherapy. Head Neck 25:833-839

10. Smith RV, Kotz T, Beitler JJ, Wadler S (2000) Long-term swallowing problems after organ preservation therapy with concomitant radiotherapy and intravenous hydroxyurea: initial results. Arch Otolaryngol Head Neck Surg 126:384-389

11. Kotz T, Abraham S, Beitler JJ, Wadler S, Smith RV (1999) Pharyngeal transport dysfunction consequent to an organ-sparing protocol. Arch Otolaryngol Head Neck Surg 125:410-413

12. Murry T, Madasu R, Martin A, Robbins KT (1998) Acute and chronic changes in swallowing and quality of life following intraarterial chemoradiotherapy for organ preservation in patients with advanced head and neck cancer. Head Neck 20:31-37 
13. Kotz T, Costello R, Li Y, Posner MR (2004) Swallowing dysfunction after chemoradiotherapy for advanced squamous cell carcinoma of the head and neck. Head Neck 26:365-372

14. Shiley SG, Hargunani CA, Skoner JM, Holland JM, Wax MK (2006) Swallowing function after chemoradiotherapy for advanced stage oropharyngeal cancer. Otolaryngol Head Neck Surg 134:455-459

15. Gaziano JE (2002) Evaluation and management of oropharyngeal Dysphagia in head and neck cancer. Cancer Control 9:400-409

16. Rankin KV (2000) Oral health in cancer therapy: evaluating and preventing oral complications. Dent Today 19:60-65

17. Lazarus CL (1993) Effects of radiotherapy therapy and voluntary maneuvers on swallow functioning in head and neck cancer patients. Clin Commun Disord 3:11-20

18. Dijkstra PU, Kalk WW, Roodenburg JL (2004) Trismus in head and neck oncology: a systematic review. Oral Oncol 40:879-889

19. Logemann JA (1998) Evaluation and treatment of swallowing disorders, 2nd edn. Pro-Ed, Austin, TX

20. Lazarus CL, Logemann JA, Rademaker A, Kahrilas PJ (2002) Effects of voluntary maneuvres on tongue base function for swallowing. Folia Phoniatr Logop 54:171-176

21. Logemann JA, Pauloski BR, Rademaker AW, Colangelo LA (1997) Super-supraglottic swallow in irradiated head and neck cancer patients. Head Neck 19:535-540

22. Abdel-Wahab M, Abitbol A, Lewin A, Troner M, Hamilton K, Markoe A (2005) Quality-of-life assessment after hyperfractionated radiotherapy therapy and 5-fluorouracil, cisplatin, and paclitaxel (Taxol) in inoperable and/or unresectable head and neck squamous cell carcinoma. Am J Clin Oncol 28:359-366

23. Ackerstaff AH, Tan IB, Rasch CR, Balm AJ, Keus RB, Schornagel JH, Hilgers FJ (2002) Quality-of-life assessment after supradose selective intra-arterial cisplatin and concomitant radiotherapy (RADPLAT) for inoperable stage IV head and neck squamous cell carcinoma. Arch Otolaryngol Head Neck Surg 128:1185-1190

24. Adelstein DJ, Saxton JP, Lavertu P, Rybicki LA, Esclamado RM, Wood BG, Strome M, Carroll MA (2002) Maximizing local control and organ preservation in stage IV squamous cell head and neck cancer with hyperfractionated radiotherapy and concurrent chemotherapy. J Clin Oncol 20:1405-1410

25. Akst LM, Chan J, Elson P, Saxton J, Strome M, Adelstein D (2004) Functional outcomes following chemoradiotherapy for head and neck cancer. Otolaryngol Head Neck Surg 131:950-957

26. Albuquerque K, Cirrone J, Aziz H, Har-El G, Sundaram K, Dipillo F, Fulton L, Aral I, Schulsinger A, Rotman M (2001) Quality of life with functional pharyngeal preservation in advanced carcinomas of the base tongue complex using an integrated trimodality approach. Am J Clin Oncol 24:623-627

27. Arraras Urdaniz JI, Arias de la Vega F, Manterola Burgaleta A, Vera Garcia R, Martinez Aguillo M, Salgado Pascual E, Martinez Lopez E (2005) Quality of life in patients with locally advanced head and neck cancer treated with chemoradiotherapy. Comparison of two protocols using the EORTC questionnaires (QLQC30, $\mathrm{H}$ and N35). Clin Transl Oncol 7:398-403

28. Balm AJ, Rasch CR, Schornagel JH, Hilgers FJ, Keus RB, Schultze-Kool L, Ackerstaff AH, Busschers W, Tan IB (2004) Highdose superselective intra-arterial cisplatin and concomitant radiotherapy (RADPLAT) for advanced head and neck cancer. Head Neck 26:485-493

29. Barasch A, Safford M, Eisenberg E (1998) Oral cancer and oral effects of anticancer therapy. Mt Sinai J Med 65:370-377

30. Bjordal K, Hammerlid E, Ahlner-Elmqvist M, de Graeff A, Boysen M, Evensen JF, Biorklund A, de Leeuw JR, Fayers PM, Jannert M, Westin T, Kaasa S (1999) Quality of life in head and neck cancer patients: validation of the European Organization for
Research and Treatment of Cancer Quality of Life Questionnaire-H\&N35. J Clin Oncol 17:1008-1019

31. Bjordal K, Ahlner-Elmqvist M, Hammerlid E, Boysen M, Evensen JF, Biorklund A, Jannert M, Westin T, Kaasa S (2001) A prospective study of quality of life in head and neck cancer patients. Part II: longitudinal data. Laryngoscope 111:1440-1452

32. Carrara-de Angelis E, Feher O, Barros AP, Nishimoto IN, Kowalski LP (2003) Voice and swallowing in patients enrolled in a larynx preservation trial. Arch Otolaryngol Head Neck Surg 129:733-738

33. Cengiz M, Ozyar E, Esassolak M, Altun M, Akmansu M, Sen M, Uzel O, Yavuz A, Dalmaz G, Uzal C, Hicsonmez A, Sarihan S, Kaplan B, Atasoy BM, Ulutin C, Abacioglu U, Demiral AN, Hayran M (2005) Assessment of quality of life of nasopharyngeal carcinoma patients with EORTC QLQ-C30 and H\&N-35 modules. Int J Radiat Oncol Biol Phys 63:1347-1353

34. Cohen EE, Haraf DJ, List MA, Kocherginsky M, Mittal BB, Rosen F, Brockstein B, Williams R, Witt ME, Stenson KM, Kies MS, Vokes EE (2006) High survival and organ function rates after primary chemoradiotherapy for intermediate-stage squamous cell carcinoma of the head and neck treated in a multicenter phase II trial. J Clin Oncol 24:3438-3444

35. El Deiry M, Funk GF, Nalwa S, Karnell LH, Smith RB, Buatti JM, Hoffman HT, Clamon GH, Graham SM, Trask DK, Dornfeld KJ, Yao M (2005) Long-term quality of life for surgical and nonsurgical treatment of head and neck cancer. Arch Otolaryngol Head Neck Surg 131:879-885

36. Epstein JB, Beaumont JL, Gwede CK, Murphy B, Garden AS, Meredith R, Le QT, Brizel D, Isitt J, Cella D (2007) Longitudinal evaluation of the oral mucositis weekly questionnaire-head and neck cancer, a patient-reported outcomes questionnaire. Cancer 109:1914-1922

37. Fang FM, Tsai WL, Chien CY, Chiu HC, Wang CJ, Chen HC, Hsiung CY (2005) Changing quality of life in patients with advanced head and neck cancer after primary radiotherapy or chemoradiotherapy. Oncology 68:405-413

38. Franzmann EJ, Lundy DS, Abitbol AA, Goodwin WJ (2006) Complete hypopharyngeal obstruction by mucosal adhesions: a complication of intensive chemoradiotherapy for advanced head and neck cancer. Head Neck 28:663-670

39. Fung K, Lyden TH, Lee J, Urba SG, Worden F, Eisbruch A, Tsien C, Bradford CR, Chepeha DB, Hogikyan ND, Prince ME, Teknos TN, Wolf GT (2005) Voice and swallowing outcomes of an organ-preservation trial for advanced laryngeal cancer. Int $\mathrm{J}$ Radiat Oncol Biol Phys 63:1395-1399

40. Goguen LA, Posner MR, Norris CM, Tishler RB, Wirth LJ, Annino DJ, Gagne A, Sullivan CA, Sammartino DE, Haddad RI (2006) Dysphagia after sequential chemoradiation therapy for advanced head and neck cancer. Otolaryngol Head Neck Surg 134:916-922

41. Gourin CG, McAfee WJ, Neyman KM, Howington JW, Podolsky RH, Terris DJ (2005) Effect of comorbidity on quality of life and treatment selection in patients with squamous cell carcinoma of the head and neck. Laryngoscope 115:1371-1375

42. Graner DE, Foote RL, Kasperbauer JL, Stoeckel RE, Okuno SH, Olsen KD, Sabri AN, Maragos NE, Cha SS, Sargent DJ, Strome SE (2003) Swallow function in patients before and after intraarterial chemoradiotherapy. Laryngoscope 113:573-579

43. Guadagnolo BA, Haddad RI, Posner MR, Weeks L, Wirth LJ, Norris CM, Sullivan CA, Goguen L, Busse PM, Tishler R (2005) Organ preservation and treatment toxicity with induction chemotherapy followed by radiation therapy or chemoradiation for advanced laryngeal cancer. Am J Clin Oncol 28:371-378

44. Hanna E, Sherman A, Cash D, Adams D, Vural E, Fan CY, Suen JY (2004) Quality of life for patients following total laryngec- 
tomy vs chemoradiotherapy for laryngeal preservation. Arch Otolaryngol Head Neck Surg 130:875-879

45. Hillman RE, Walsh MJ, Wolf GT, Fisher SG, Hong WK (1998) Functional outcomes following treatment for advanced laryngeal cancer. Part I--Voice preservation in advanced laryngeal cancer. Part II-laryngectomy rehabilitation: the state of the art in the VA System. Research speech-language pathologists. Department of Veterans Affairs Laryngeal Cancer Study Group. Ann Otol Rhinol Laryngol Suppl 172:1-27

46. Jereczek-Fossa BA, Santoro L, Alterio D, Franchi B, Fiore MR, Fossati P, Kowalczyk A, Canino P, Ansarin M, Orecchia R (2007) Fatigue during head-and-neck radiotherapy: prospective study on 117 consecutive patients. Int J Radiat Oncol Biol Phys 68:403-415

47. Kulbersh BD, Rosenthal EL, McGrew BM, Duncan RD, McColloch NL, Carroll WR, Magnuson JS (2006) Pretreatment, preoperative swallowing exercises may improve dysphagia quality of life. Laryngoscope 116:883-886

48. Lazarus CL, Logemann JA, Pauloski BR, Rademaker AW, Larson CR, Mittal BB, Pierce M (2000) Swallowing and tongue function following treatment for oral and oropharyngeal cancer. J Speech Lang Hear Res 43:1011-1023

49. Lee JS, Iranmanesh A, Schmidt BL, Fischbein NJ, McKenna SJ (2005) Limited oral opening in a 43-year-old man. J Oral Maxillofac Surg 63:103-108

50. List MA, Mumby P, Haraf D, Siston A, Mick R, MacCracken E, Vokes E (1997) Performance and quality of life outcome in patients completing concomitant chemoradiotherapy protocols for head and neck cancer. Qual Life Res 6:274-284

51. List MA, Siston A, Haraf D, Schumm P, Kies M, Stenson K, Vokes EE (1999) Quality of life and performance in advanced head and neck cancer patients on concomitant chemoradiotherapy: a prospective examination. J Clin Oncol 17:1020-1028

52. Logemann JA, Rademaker AW, Pauloski BR, Lazarus CL, Mittal BB, Brockstein B, MacCracken E, Haraf DJ, Vokes EE, Newman LA, Liu D (2006) Site of disease and treatment protocol as correlates of swallowing function in patients with head and neck cancer treated with chemoradiotherapy. Head Neck 28:64-73

53. LoTempio MM, Wang KH, Sadeghi A, Delacure MD, Juillard GF, Wang MB (2005) Comparison of quality of life outcomes in laryngeal cancer patients following chemoradiotherapy vs. total laryngectomy. Otolaryngol Head Neck Surg 132:948-953

54. Magne N, Marcy PY, Chamorey E, Guardiola E, Pivot X, Schneider M, Demard F, Bensadoun RJ (2001) Concomitant twice-aday radiotherapy and chemotherapy in unresectable head and neck cancer patients: a long-term quality of life analysis. Head Neck 23:678-682

55. Major MS, Bumpous JM, Flynn MB, Schill K (2001) Quality of life after treatment for advanced laryngeal and hypopharyngeal cancer. Laryngoscope 111:1379-1382

56. Malone JP, Stephens JA, Grecula JC, Rhoades CA, Ghaheri BA, Schuller DE (2004) Disease control, survival, and functional outcome after multimodal treatment for advanced-stage tongue base cancer. Head Neck 26:561-572

57. Marcy PY, Magne N, Bensadoun RJ, Bleuse A, Falewee MN, Viot M, Bruneton JN (2000) Systematic percutaneous fluoroscopic gastrostomy for concomitant radiochemotherapy of advanced head and neck cancer: optimization of therapy. Support Care Cancer 8:410-413

58. Mowry SE, LoTempio MM, Sadeghi A, Wang KH, Wang MB (2006) Quality of life outcomes in laryngeal and oropharyngeal cancer patients after chemoradiotherapy. Otolaryngol Head Neck Surg 135:565-570

59. Newman LA, Vieira F, Schwiezer V, Samant S, Murry T, Woodson G, Kumar P, Robbins KT (1998) Eating and weight changes following chemoradiation therapy for advanced head and neck cancer. Arch Otolaryngol Head Neck Surg 124:589-592
60. Newman LA, Robbins KT, Logemann JA, Rademaker AW, Lazarus CL, Hamner A, Tusant S, Huang CF (2002) Swallowing and speech ability after treatment for head and neck cancer with targeted intraarterial versus intravenous chemoradiotherapy. Head Neck 24:68-77

61. Nguyen NP, Sallah S, Karlsson U, Antoine JE (2002) Combined chemotherapy and radiotherapy therapy for head and neck malignancies: quality of life issues. Cancer 94:1131-1141

62. Nguyen NP, Levinson B, Dutta S, Karlsson U, Kelly KC, Dowell J, Ludin A, Sallah S (2003) Amifostine and curative intent chemoradiation for compromised cancer patients. Anticancer Res 23:1649-1656

63. Nguyen NP, Moltz CC, Frank C, Vos P, Smith HJ, Karlsson U, Dutta S, Midyett FA, Barloon J, Sallah S (2004) Dysphagia following chemoradiation for locally advanced head and neck cancer. Ann Oncol 15:383-388

64. Nguyen NP, Frank C, Moltz CC, Vos P, Smith HJ, Karlsson U, Dutta S, Midyett A, Barloon J, Sallah S (2005) Impact of dysphagia on quality of life after treatment of head-and-neck cancer. Int J Radiat Oncol Biol Phys 61:772-778

65. Nguyen NP, Frank C, Moltz CC, Vos P, Smith HJ, Bhamidipati PV, Karlsson U, Nguyen PD, Alfieri A, Nguyen LM, Lemanski C, Chan W, Rose S, Sallah S (2006) Aspiration rate following chemoradiotherapy for head and neck cancer: an underreported occurrence. Radiother Oncol 80:302-306

66. Nguyen NP, Moltz CC, Frank C, Karlsson U, Nguyen PD, Vos P, Smith HJ, Dutta S, Nguyen LM, Lemanski C, Chan W, Sallah S (2006) Dysphagia severity following chemoradiotherapy and postoperative radiotherapy for head and neck cancer. Eur J Radiol 59:453-459

67. Nguyen NP, Moltz CC, Frank C, Vos P, Millar C, Smith HJ, Lee H, Karlsson U, Nguyen PD, Martinez T, Nguyen LM, Sallah S (2007) Aspiration rate following nonsurgical therapy for laryngeal cancer. ORL J Otorhinolaryngol Relat Spec 69:116-120

68. Nguyen NP, Vos P, Smith HJ, Nguyen PD, Alfieri A, Karlsson U, Dutta S, Lemanski C, Nguyen LM, Sallah S (2007) Concurrent chemoradiation for locally advanced oropharyngeal cancer. Am J Otolaryngol 28:3-8

69. Oates JE, Clark JR, Read J, Reeves N, Gao K, Jackson M, Boyer M, O'brien CJ (2007) Prospective evaluation of quality of life and nutrition before and after treatment for nasopharyngeal carcinoma. Arch Otolaryngol Head Neck Surg 133:533-540

70. Ohrn KE, Sjoden PO, Wahlin YB, Elf M (2001) Oral health and quality of life among patients with head and neck cancer or haematological malignancies. Support Care Cancer 9:528-538

71. Ozyar E, Cengiz M, Gurkaynak M, Atahan IL (2005) Trismus as a presenting symptom in nasopharyngeal carcinoma. Radiother Oncol 77:73-76

72. Pauloski BR, Rademaker AW, Logemann JA, Lazarus CL, Newman L, Hamner A, MacCracken E, Gaziano J, Stachowiak L (2002) Swallow function and perception of dysphagia in patients with head and neck cancer. Head Neck 24:555-565

73. Pauloski BR, Rademaker AW, Logemann JA, Newman L, MacCracken E, Gaziano J, Stachowiak L (2006) Relationship between swallow motility disorders on videofluorography and oral intake in patients treated for head and neck cancer with radiotherapy with or without chemotherapy. Head Neck 28:1069-1076

74. Rademaker AW, Vonesh EF, Logemann JA, Pauloski BR, Liu D, Lazarus CL, Newman LA, May AH, MacCracken E, Gaziano J, Stachowiak L (2003) Eating ability in head and neck cancer patients after treatment with chemoradiotherapy: a 12-month follow-up study accounting for dropout. Head Neck 25:1034-1041

75. Rieger JM, Zalmanowitz JG, Wolfaardt JF (2006) Functional outcomes after organ preservation treatment in head and neck cancer: a critical review of the literature. Int J Oral Maxillofac Surg 35:581-587 
76. Terrell JE, Fisher SG, Wolf GT (1998) Long-term quality of life after treatment of laryngeal cancer. The Veterans Affairs Laryngeal Cancer Study Group. Arch Otolaryngol Head Neck Surg 124:964-971

77. Trotti A, Bellm LA, Epstein JB, Frame D, Fuchs HJ, Gwede CK, Komaroff E, Nalysnyk L, Zilberberg MD (2003) Mucositis incidence, severity and associated outcomes in patients with head and neck cancer receiving radiotherapy with or without chemotherapy: a systematic literature review. Radiother Oncol 66:253262

78. van den Berg MG, Rasmussen-Conrad EL, Gwasara GM, Krabbe PF, Naber AH, Merkx MA (2006) A prospective study on weight loss and energy intake in patients with head and neck cancer, during diagnosis, treatment and revalidation. Clin Nutr 25:765-772

79. van den Broek GB, Balm AJ, van den Brekel MW, Hauptmann M, Schornagel JH, Rasch CR (2006) Relationship between clinical factors and the incidence of toxicity after intra-arterial chemoradiotherapy for head and neck cancer. Radiother Oncol 81:143150

80. Vokes EE, Stenson K, Rosen FR, Kies MS, Rademaker AW, Witt ME, Brockstein BE, List MA, Fung BB, Portugal L, Mittal BB, Pelzer H, Weichselbaum RR, Haraf DJ (2003) Weekly carboplatin and paclitaxel followed by concomitant paclitaxel, fluorouracil, and hydroxyurea chemoradiotherapy: curative and organpreserving therapy for advanced head and neck cancer. J Clin Oncol 21:320-326

81. Eisbruch A, Lyden T, Bradford CR, Dawson LA, Haxer MJ, Miller AE, Teknos TN, Chepeha DB, Hogikyan ND, Terrell JE, Wolf GT (2002) Objective assessment of swallowing dysfunction and aspiration after radiotherapy concurrent with chemotherapy for head-and-neck cancer. Int J Radiat Oncol Biol Phys 53:23-28

82. Eisbruch A, Shewach DS, Bradford CR, Littles JF, Teknos TN, Chepeha DB, Marentette LJ, Terrell JE, Hogikyan ND, Dawson LA (2001) Radiotherapy concurrent with gemcitabine for locally advanced head and neck cancer: a phase I trial and intracellular drug incorporation study. J Clin Oncol 19:792-799

83. Moore A, McQuay A, Gray JAM (1995) Evidence-based everything, 12 edn. Bandolier

84. Karnell MP, McCracken E (1994) A data base information storage and reporting system for videofluorographic oropharyngeal motility swallowing evaluation. Am J Speech Lang Pathol 8:54-60

85. Hassan SJ, Weymuller EA Jr (1993) Assessment of quality of life in head and neck cancer patients. Head Neck 15:485-496

86. Cella DF, Tulsky DS, Gray G, Sarafian B, Linn E, Bonomi A, Silberman M, Yellen SB, Winicour P, Brannon J (1993) The functional assessment of cancer therapy scale: development and validation of the general measure. J Clin Oncol 11:570-579

87. Bonomi AE, Cella DF, Hahn EA, Bjordal K, Sperner-Unterweger B, Gangeri L, Bergman B, Willems-Groot J, Hanquet P, Zittoun R (1996) Multilingual translation of the functional assessment of cancer therapy (FACT) quality of life measurement system. Qual Life Res 5:309-320

88. Aaronson NK, Ahmedzai S, Bergman B, Bullinger M, Cull A, Duez NJ, Filiberti A, Flechtner H, Fleishman SB, de Haes JC (1993) The European Organization for Research and Treatment of Cancer QLQ-C30: a quality-of-life instrument for use in international clinical trials in oncology. J Natl Cancer Inst 85:365376

89. Groenvold M, Klee MC, Sprangers MA, Aaronson NK (1997) Validation of the EORTC QLQ-C30 quality of life questionnaire through combined qualitative and quantitative assessment of patient-observer agreement. J Clin Epidemiol 50:441-450

90. Hjermstad MJ, Fossa SD, Bjordal K, Kaasa S (1995) Test/retest study of the European Organization for Research and Treatment of Cancer Core Quality-of-Life Questionnaire. J Clin Oncol 13:1249-1254

91. Bjordal K, de Graeff A, Fayers PM, Hammerlid E, van Pottelsberghe C, Curran D, Ahlner-Elmqvist M, Maher EJ, Meyza JW, Bredart A, Soderholm AL, Arraras JJ, Feine JS, Abendstein H, Morton RP, Pignon T, Huguenin P, Bottomly A, Kaasa S (2000) A 12 country field study of the EORTC QLQ-C30 (version 3.0) and the head and neck cancer specific module (EORTC QLQH\&N35) in head and neck patients. EORTC Quality of Life Group. Eur J Cancer 36:1796-1807

92. Sherman AC, Simonton S, Adams DC, Vural E, Owens B, Hanna E (2000) Assessing quality of life in patients with head and neck cancer: cross-validation of the European Organization for Research and Treatment of Cancer (EORTC) Quality of Life Head and Neck module (QLQ-H\&N35). Arch Otolaryngol Head Neck Surg 126:459-467

93. Cox JD, Stetz J, Pajak TF (1995) Toxicity criteria of the Radiotherapy Therapy Oncology Group (RTOG) and the European Organization for Research and Treatment of Cancer (EORTC). Int J Radiat Oncol Biol Phys 31:1341-1346

94. Kiebert G, Kaasa S (1993) Quality of Life in clinical trials: experience and perspective of the EORTC. J Natl Cancer Inst 85:365376

95. List MA, Ritter-Sterr C, Lansky SB (1990) A performance status scale for head and neck cancer patients. Cancer 66:564-569

96. List MA, D'Antonio LL, Cella DF, Siston A, Mumby P, Haraf D, Vokes E (1996) The performance status scale for head and neck cancer patients and the functional assessment of cancer therapyhead and neck scale. A study of utility and validity. Cancer 77:2294-2301

97. Carroll WR, Locher JL, Canon CL, Bohannon IA, McColloch NL, Magnuson JS (2008) Pretreatment swallowing exercises improve swallow function after chemoradiation. Laryngoscope 118(1):39-43

98. Hind JA, Nicosia MA, Roecker EB, Carnes ML, Robbins J (2001) Comparison of effortful and noneffortful swallows in healthy middle-aged and older adults. Arch Phys Med Rehabil 82:1661-1665

99. Logemann JA, Pauloski BR, Rademaker AW, Colangelo LA (1997) Speech and swallowing rehabilitation for head and neck cancer patients. Oncology (Williston Park) 11:651-6, 659

100. Ohmae Y, Logemann JA, Kaiser P, Hanson DG, Kahrilas PJ (1996) Effects of two breath-holding maneuvers on oropharyngeal swallow. Ann Otol Rhinol Laryngol 105:123-131

101. Robin DA, Goel A, Somodi LB, Luschei ES (1992) Tongue strength and endurance: relation to highly skilled movements. J Speech Hear Res 35:1239-1245

102. Veis S, Logemann JA, Colangelo L (2000) Effects of three techniques on maximum posterior movement of the tongue base. Dysphagia 15:142-145

103. Logemann JA, Pauloski BR, Rademaker AW, Lazarus CL, Gaziano J, Stachowiak L, Newman L, MacCracken E, Santa D, Mittal B (2008) Swallowing disorders in the first year after radiotherapy and chemoradiotherapy. Head Neck 30(2):148-158

104. Langerman A, MacCracken E, Kasza K, Haraf DJ, Vokes EE, Stenson KM (2007) Aspiration in chemoradiated patients with head and neck cancer. Arch Otolaryngol Head Neck Surg 133:1289-1295

105. Hilgers FJ, Ackerstaff AH (2000) Comprehensive rehabilitation after total laryngectomy is more than voice alone. Folia Phoniatr Logop 52:65-73

106. Buchbinder D, Currivan RB, Kaplan AJ, Urken ML (1993) Mobilization regimens for the prevention of jaw hypomobility in the radiated patient: a comparison of three techniques. J Oral Maxillofac Surg 51:863-867 